Conclusion The power of the project is its simplicity. It creates time and space for conversation about what has become a taboo subject in a non-threatening way. As such it has provided a model for future forms of engagement and in particular has contributed to the establishment of a support group for people affected by sudden loss such as death by accident or suicide.

\section{P-62 IMPROVING SUPPORT AND UNDERSTANDING IN OUR COMMUNITY FOR PEOPLE AFFECTED BY A LIFE- LIMITING ILLNESS}

Warren Finney. Prospect Hospice, Swindon, UK

10.1136/bmjspcare-2017-hospice.89

Background Prospect Hospice strives for excellent end-of-life care for everyone. We also recognise that we cannot meet everyone with a life-limiting illness in our community. A key activity for us is to improve the recognition and understanding across Swindon of the importance of end-of-life care. After the National Council for Palliative Care launched the Dying Matters Dying Well Community Charter (DWCC) in 2015, we joined with local organisations to create our own Swindon Charter.

Aims To improve support and understanding for anyone affected by end-of-life care in the workplace.

Methods With partners, Healthwatch, the CCG, Great Western Hospital, Swindon Carers Centre and Swindon Borough Council we:

- Surveyed local people on what was important to them.

- Held a launch conference.

- Created print and social media activity and presentations.

- Created a set of offers and asks of local organisations.

- Promoted the Charter on the local authority-sponsored My Care My Support website.

- Undertook targeted engagement activity with employers to secure sign-up and implement the charter in their workplace.

Results In May 2016, nearly 90 people from local employers, health and social care organisations and community groups attended a launch conference to learn about our charter. We then targeted local employers to agree actions and activities to promote the Charter asking for commitment to two activities to make a difference, such as:

- Creating a Bereavement/Compassionate leave policy.

- Reviewing policies and procedures to reflect the aims of the Charter.

- Creating flexibility in the workplace and demonstrate how this was achieved.

- Signposting to useful external advice and the support the employer offers.

- Promoting the My Care My Support website.

- Nominating a single point of contact for key information.

Currently 17 organisations, with a combined reach of 12000 people, have signed up to the Charter, implementing various changes across the workplace to make a real difference, and we have only just begun!
P-63 BUILDING COMPASSIONATE COMMUNITIES ACROSS LONDON AND THE SOUTH EAST

${ }^{1}$ Carly Attridge, ${ }^{2}$ Heather Richardson, 'Sally Muylders. ${ }^{1}$ St Joseph's Hospice, London, UK; ${ }^{2} S t$ Christopher's Hospice, London, UK

\subsection{6/bmjspcare-2017-hospice.90}

Background A London hospice has played an important part at successfully developing a Compassionate Community in their area. With significant funding it will be replicating the project, working with up to seven other hospices or similar organisations in and around London. Part of the success of the project has been to reach communities who do not traditionally access hospice care. We want to extend this opportunity to other hospices also committed to issues of increased reach and equity.

Aims Our aim is to build a wider network of Compassionate Neighbours who are supporting people in their local communities; we will test and learn whether the success of the original London project can be replicated in other areas, and which ingredients are vital for success. Our ultimate aim is to create a social movement establishing a network of Compassionate Communities across the country, starting in London.

Methods The hospice will train and mentor other hospices to replicate the project in their own area. It will draw on the skills of compassionate neighbours as well as project leads. Our evaluation of the programme will form the basis of plans for a national roll out and inform reciprocal learning with other organisations also involved in large scale use of volunteers to address societal issues.

Results Our learning will confirm whether replication of this project is possible. We will be evaluating the quality and quantity of social connexions on the part of project participants and their relationships in their local communities and with their local hospice. We should have early results available for the conference.

Conclusion This is an important project focused on upscaling a successful hospice initiative. It will provide insights into the role of community participation in end of life and how hospices can be part of that.

\section{Creative arts and therapies}

\section{P-64 EVALUATION OF A HOSPICE-BASED DANCE PROGRAMME FOR PEOPLE WITH PARKINSON'S DISEASE}

Margaret Clifford, John Dixon, Simon Robey. St Joseph's Hospice, London, UK

10.1136/bmjspcare-2017-hospice.91

Introduction Published evidence suggests that dance may be of benefit to people with Parkinson's disease. Following a suggestion from a service-user, our hospice set up a pilot dance programme for people with Parkinson's disease comprising six fortnightly 1.5 hour dance classes over 12 weeks.

Aim To share our experience of setting up a hospice Parkinson's dance programme and evaluate the impact on participants.

Methods Parkinson's Disease Questionnaire (PDQ-39), a validated quality of life measure for Parkinson's disease was 